\title{
A New Antiwear Additive/Surface Pretreatment for PFPE Liquid Lubricants
}

Wilfredo Morales and Robert L. Fusaro

Lewis Research Center

Cleveland, Ohio

Mark Siebert and Theo Keith

University of Toledo

Toledo, Ohio

Ralph Jansen and Pilar Herrera-Fierro

Ohio Aerospace Institute

Brook Park, Ohio

December 1995

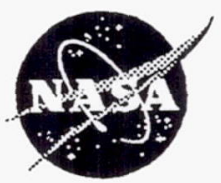

National Aeronautics and Space Administration 


\title{
A NEW ANTIWEAR ADDITIVE/SURFACE PRETREATMENT FOR PFPE LIQUID LUBRICANTS
}

\author{
Wilfredo Morales and Robert L. Fusaro \\ National Aeronautics and Space Administration \\ Lewis Research Center \\ Cleveland, Ohio 44135 \\ Mark Siebert and Theo Keith \\ University of Toledo \\ and
}

Ralph Jansen \& Pilar Herrera-Fierro

Ohio Aerospace Institute

\section{ABSTRACT}

Pin-on-Disk tribology experiments were conducted on a perfluoroalkylether (PFPE) liquid lubricant with and without a new PFPE lubricant antiwear additive material, a silane. It was found that the silane provided moderate improvement in the antiwear performance of the PFPE lubricant when applied to the metallic surface as a surface coating or when added to the PFPE as a dispersion (emulsion). Slightly better results were obtained by using the combination of a surface coating and an emulsion of the silane. The silane emulsions or coatings did not affect the friction properties of the lubricant. Micro-Fourier Transformation Infrared ( $\mu$ FTIR) spectroscopy analysis was performed to study silane transfer films and the degradation of the PFPE. The silane was found to mitigate degradation of the PFPE which may have been the major reason for the improved antiwear performance observed.

\section{INTRODUCTION}

A class of high molecular weight liquid perfluoro ethers, which were designated perfluoropolyalkylethers (PFPEs), was synthesized in the 1960s (1,2). These liquids possessed excellent high temperature stability and low vaporization pressures and thus were immediately recognized to have potential for use in aerospace applications. While PFPEs have been used successfully as diffusion pump oils (3), dielectric fluids (4), and as lubricants (5), their potential as outstanding aerospace lubricants has not been realized. The main reason has been that they tend to decompose under boundary lubrication conditions generating extremely reactive fluorinated products that can attack metal surfaces leading to increased wear and corrosion.

One method for mitigating PFPE decomposition is by the use of soluble additives in the liquid lubricant, but the difficulty is that known additives for hydrocarbon-based liquid lubricants are not soluble in the PFPEs. This has led to studies $(6,7)$ investigating the use of highly fluorinated compounds as potential soluble additives for 
PFPEs. One possible drawback for the use of fluorinated additives is that many of these compounds have much lower vapor pressures than the PFPEs. Another drawback is that these additives may decompose, generating reactive fluorinated products.

Static thermal tests have shown that PFPEs decompose at elevated temperatures in the presence of certain metal oxides or metal fluorides, and it has been suggested that active Lewis acid sites on metal oxides or fluorides are responsible for PFPE catalytic decomposition (8-10). Recent studies, however, have indicated that Lewis acid sites may not be responsible for decomposition (11-13). For example, $\mathrm{Ng}$ et al. (12) observed that perfluorodiethylether decomposed on both untreated and pyridine treated dehydroxylated aluminum oxide surfaces. Since pyridine is a compound widely used to block the action of Lewis acids, the results suggested that Lewis acid sites were not the reason for decomposition. $\mathrm{Ng}$ et al. also observed that perfluorodiethyl ether did not decompose on dehydroxylated alumina surfaces treated with a $\left(\mathrm{CH}_{3}\right)_{3}-\mathrm{SiCl}$ vapor. They suggested that the following reaction took place which passivated (silylated) the alumina surfaces:

$$
\mathrm{Al}-\mathrm{OH}+\mathrm{ClSi}-\left(\mathrm{CH}_{3}\right)_{3} \rightarrow \mathrm{Al}-\mathrm{O}-\mathrm{Si}\left(\mathrm{CH}_{3}\right)_{3}+\mathrm{HCl}
$$

Morales (13) decomposed a commercial PFPE on both alpha and gamma alumina surfaces at and above $200^{\circ} \mathrm{C}$. He found that a pyridine treatment of the alumina surfaces did not prevent PFPE decomposition. He did observed, however, that by treating the surfaces of the alumina with various liquid silanes the decomposition of the PFPE's was mitigated. Surface treatment with one particular silane, 3-aminopropyltriethoxysilane, prevented decomposition up to $350^{\circ} \mathrm{C}$.

The static decomposition studies by $\mathrm{Ng}$ et al. and Morales led to the idea of using a silane to minimize PFPE decomposition and the wear of the sliding surfaces under boundary lubrication conditions. To evaluate this concept, an experimental program was developed using a pin-on-disk tribometer to investigate the friction, wear and degradation of a PFPE oil under boundary lubrication conditions over short and long term sliding conditions. The silane was applied as a coating to the sliding specimens or as a dispersion (emulsion) to the PFPE liquid. Optical Microscopy and Micro Fourier Transformation Infrared ( $\mu$ FTIR) microscopy examinations of the oil and surfaces were conducted to evaluate decomposition products. 


\section{EXPERIMENTAL}

Test Variables

To study the effect of a silane coating and/or emulsion on the friction, wear, and degradation properties of a perfluoropolyether (PFPE) oil the following conditions were evaluated: (1) silane emulsion, (2) silane disk coating,

(3) silane disk and pin coatings, (4) silane emulsion and silane disk coating (5) silane emulsion and pin and disk coatings,

(6) no treatment.

\section{Materials}

The disks used were made of $440 \mathrm{C}$ stainless steel with a Rockwell hardness of C-57 to C-59. The disks were lapped and polished to a surface finish of $0.040 \pm 0.015 \mu \mathrm{m}$ CLA (centerline average). Instead of using pins, the pin holder was modified to hold $0.476 \mathrm{~cm}$ radius ( $3 / 8$ inch diameter) commercial grade $10,440 \mathrm{C}$ balls which had the same surface roughness as the disks. The hardness of the balls was Rockwell C- 60 .

Properties of the PFPE and silane (3-aminopropyltriethoxysilane) liquids used in this study are given in Table 1 and the following are the structures:

The perfluoropolyalkylether.

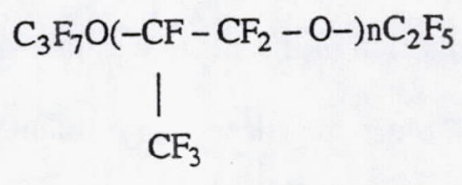

The silane

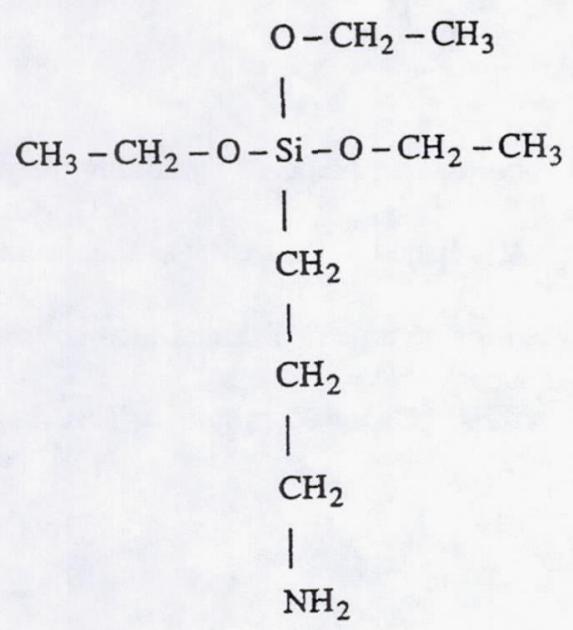




\section{Friction and Wear Apparatus}

The pin-on-disk tribometer used in this study (Fig. 1) has been described in detail in reference (14). The specimens consisted of a flat rotating disk (6.3-cm diameter) in sliding contact with a stationary pin (ball) (0.476$\mathrm{cm}$ radius) which was securely fastened in a holder. The ball slid on disk tracks that ranged from $4.8 \mathrm{~cm}$ to $3.7 \mathrm{~cm}$ in diameter. The rotational speed of the disk was controlled at $200 \mathrm{rpm}$ giving linear sliding speeds of 0.16 to 0.12 $\mathrm{m} / \mathrm{s}$. The test specimens were encased in a plastic box to control the atmospheric humidity. A load of $2 \mathrm{~kg}$ was applied to the ball, which gave an initial hertzian contact stress of $1.3 \mathrm{GPa}(190,000 \mathrm{psi})$. A polyethylene ring was fastened around the diameter and extended approximately $0.4 \mathrm{~cm}$ above the surface of the disk to restrain the oil from being thrown from the disk by centrifugal forces. The amount of oil used for each test was $2.0 \mathrm{~g}$.

\section{Surface Cleaning}

The ball and disk cleaning procedure was as follows:

(1) Wash surfaces with ethyl alcohol. (2) Rub surfaces with a water paste of polishing alumina (particle size 0.3 $\mu \mathrm{m})$. Clean until water readily wetted the surfaces. (3) Scrub surfaces under running tap water with a brush to remove alumina. (4) Rinse in deionized water. (5) Dry surfaces by blowing on with clean compressed air.

\section{Emulsion Preparation}

A one percent (by weight) emulsion of the silane was prepared by first adding the appropriate amount of the silane to the PFPE in a test tube. Since the silane was insoluble in the PFPE, the test tube was placed in an ultrasonic cleaner for ten minutes to mix the two liquids. The ultrasonic agitation caused the formation of a milky white emulsion.

\section{Coating Application}

A one percent (by weight) of the silane in a methanol solution was prepared by adding the appropriate amount of the silane to $100 \mathrm{ml}$ of methanol in a $500 \mathrm{ml}$ beaker. A polished $440 \mathrm{C}$ disk was then immersed into this solution for 15 minutes. The disk was carefully withdrawn, placed inside a petri dish and then covered. The covered petri dish was then placed inside a furnace (maintained at $200^{\circ} \mathrm{C}$ ) for 30 minutes. This method produced a coating of approximately $3 \mu \mathrm{m}$ thick. 


\section{Emulsion Stability Testing}

A small quantity of the emulsion was poured into a sample bottle, sealed, and left stand for two months. Periodic visual inspection was conducted to check for separation. In addition, a small quantity of the emulsion was placed in a centrifuge and spun at $2500 \mathrm{rpm}$ at a radius of $10 \mathrm{~cm}$ for 10 minutes. In an additional test, some of the emulsion was heated in glassware at $250^{\circ} \mathrm{C}$ for 30 minutes under a partial vacuum $(<5$ Torr).

\section{Thermal Gravimetric Analysis Testing}

Thermal gravimetric analysis (TGA) tests were conducted on the pure PFPE, the silane and the mixture. A small quantity of each liquid was injected onto an aluminum pan, and the pan was then loaded and sealed (under a flowing $\mathrm{N}_{2}$ atmosphere at $60 \mathrm{ml} / \mathrm{min}$ ) inside the TGA system. The TGA temperature was ramped at a rate of $10^{\circ} \mathrm{C}$ per minute from room temperature to $360^{\circ} \mathrm{C}$.

\section{Friction and Wear Testing}

Two grams of oil (with or without the emulsion) were applied to the disk (with attached polyethylene ring). The ball (securely fastened in its holder) and disk were inserted into the friction and wear apparatus and properly aligned. The test chamber was then sealed and purged with dry air (100 ppm moisture content) for 15 minutes before commencing the tests. This purge was continued throughout the tests. After the 15-minute purge, the disk was set into rotation at $200 \mathrm{rpm}$ and a 2-kilogram load was gradually applied to the ball. The test temperature was $25^{\circ} \mathrm{C}$.

Each test was stopped after 1 kilocycle $(\mathrm{kc})$ of sliding. At $200 \mathrm{rpm}$ this is 5 minutes. The ball holder was removed from the apparatus and the wear area on the ball was examined by optical microscopy and a wear measurement made. The holder was then placed back into the apparatus and the previous test procedure repeated. The ball was not removed from its holder, and locating marks insured that the holder was returned to its original position.

Each test was stopped and the above procedure repeated after sliding intervals of 3, 7, 15, 30 and $50 \mathrm{kc}$ of sliding. Some tests were terminated at this point and some tests were continued for long duration sliding effects. The long duration tests were run continuously for up to two weeks [4300 kc $(500 \mathrm{~km})$ ], being stopped once a day (or after the weekend) to examine the ball wear scars and measure wear. Disk wear tracks were examined by optical microscopy after the tests were terminated (either $50 \mathrm{kc}$ or the long duration tests). 
To determine the friction and wear protection of the silane coating in a stand alone condition, some tests were conducted on the silane coating without using any PFPE lubricant. Similar testing conditions were applied.

\section{Data Analysis}

The data analysis was performed by first entering the distance and wear volume for every sliding interval for each test into a computer spreadsheet. Short term data analysis considered data taken from the start of the test up to $5000 \mathrm{~m}$ of sliding. Five data points were typically recorded in this period. A least squares regression fit which was forced to intersect the origin was used to determine the short term wear rate for each test. Tests were grouped by treatment type and the mean, maximum, minimum and standard deviation values were calculated.

Long term data analysis was conducted using a similar procedure except that only data collected between $25 \mathrm{~km}$ of sliding and the end of the test were considered. The least squares regression fit in this case was not forced to intersect the origin for the determination of the long term wear rates. The same statistics were calculated for each group of long term tests.

\section{Sliding Surfaces Analysis}

Optical microscopy techniques were used to study the lubrication films, the transfer films, and wear debris. The surfaces were viewed at magnifications to 1000 .

A micro-fourier transformation infrared ( $\mu$ FTIR) microscope was also used to observe selected wear surfaces after either $50 \mathrm{kc}$ of sliding or after the long duration tests $(\sim 300 \mathrm{kc})$. For information about the operation and use of this spectrometer see references (15-17). The observations were done in the reflectance mode. A gold coated glass slide was used as a background and the area of analysis was a $100 \mu \mathrm{m}$ diameter circle. The ball and disk wear areas were at least $300 \mu \mathrm{m}$ wide, therefore several spots within the track were analyzed in order to obtain a better perspective of the surface composition. For comparison, off wear scar areas were also analyzed. Before commencing the $\mu$ FTIR analysis, the specimens were rinsed with freon and then cleaned in an ultrasonic cleaner to remove excess lubricant in order to obtain access to the deposits on the surface interface. A surface profilometer was also used to examine the cleaned disk wear surfaces. 


\section{RESULTS AND DISCUSSION}

Emulsion Stability Tests

Visual inspection of the silane/PFPE emulsion that was left stand for two months on a shelf revealed the persistence of a milky white color, indicating that the two constituents did not separate. In addition, no separation of the two materials was found to occur in centrifuge testing at $2500 \mathrm{rpm}$ for 10 minutes. Because of these tests, the emulsion was judged to be exceptionally stable.

Thermogravometric Analysis (TGA) testing of the emulsion and each constituent were also conducted. Figure 2 shows the results. The TGA thermogram for the pure silane (Fig. 2a) showed that nearly all the silane had evaporated by $140^{\circ} \mathrm{C}$, whereas the TGA thermogram for the pure PFPE (Fig. 2b) showed that the PFPE started to evaporate at about $270^{\circ} \mathrm{C}$. The TGA thermogram for the emulsion was the same as that of the pure PFPE (Fig. $2 \mathrm{~b}$ ). There was no evidence of silane evaporation from the emulsion in the TGA tests; however, the amount of silane present may have been too small to detect.

Because of the TGA results, it was decided to subject the emulsion to a temperature that was higher than the boiling point of the silane but lower than that of the PFPE. Thus, the emulsion was heated under a partial vacuum to $250^{\circ} \mathrm{C}$, held at temperature for 30 minutes and then cooled to room temperature. The emulsion still maintained its milky white color and no separation could be observed, indicating no evaporation of the silane had occurred. Vapor pressure measurements of the pure liquids and the emulsion will be conducted in the future to supplement the current work.

Ball Wear

Ball wear was evaluated for sliding distances of up to 4300 kilocycles $(\mathrm{kc})$ of sliding $(500 \mathrm{~km})$. To determine if there were differences between short term and long term effects, wear rates were calculated and compared for two sliding intervals: (1) 0 to $30 \mathrm{kc}(0$ to $4.5 \mathrm{~km})$ and (2) 50 to $4300 \mathrm{kc}(7.5$ to $500 \mathrm{~km})$. The wear as a function of sliding distance for any one particular test was nearly linear during these two sliding intervals and thus wear rates were calculated for each test using a least squares data fit.

Figure 3 shows the experimental data and a least squares fit for the first 4500 meters of sliding for the lubricant conditions of (1) silane emulsion and silane disk coating and (2) no treatment. Besides having a lower wear rate, much less data scatter was obtained for the oil emulsion/disk coating condition as compared to the no 
treatment condition. The median ball wear rate results for all the test conditions are shown in Table 2 . The table also lists the number of tests conducted under each condition, and the maximum, minimum, and standard deviation of the ball wear rates. Figure 4 gives a comparison of the median pin wear rates and the data scatter for the (a) short term tests and (b) long term tests.

For the short term tests, it was found that the silane decreased the pin wear rate by an average of about 50 percent. There did not seem to be any clear advantage of coatings over emulsions or of combining coatings with emulsions. However, should be emphasized that neither the coatings or the emulsions were optimized in this study.

In general, ball wear rates were lower for the long term tests than for the short term tests, which could be due to run-in effects. In addition, the silane did not decrease the ball wear as much for the long term tests as it did for the short term tests. A possible reason for this is that some form of mixed lubrication may be taking place. The authors have observed in unpublished data on accelerated testing devices (such as pin-on-disk and rub-shoe devices where there is 100 percent sliding) that as the wear scar gets larger, the wear rate decreases; and at some point enough pressure is generated by the liquid to cause complete separation of the surfaces. When this happens no further wear of the surfaces occurs. Mixed lubrication may be happening in these tests. The silane would not be expected to have as much beneficial effect in mixed lubrication as in pure boundary lubrication.

\section{Coefficient of Friction}

The friction results are presented in Table 3. In general, no distinguishable effect on friction coefficient was found which was dependent on either the silane emulsion or the silane coating. The maximum, minimum and median friction coefficients obtained were essentially the same for all experimental conditions. Variation from test to test under any one particular experimental condition was found to differ as much as the variation from adding a silane emulsion or a silane coating. Table 3 also presents the friction coefficient of a silane coating (run dry under the same conditions), for comparison purposes. In the dry condition, the silane coating lasted less than $0.75 \mathrm{~km}$ $(5 \mathrm{kc})$ of sliding.

\section{Optical Microscopy}

A comparison of the ball wear surfaces after $2 \mathrm{~km}$ of sliding is shown in Fig. 5 for the following tests: (a) a silane emulsion, (2) a silane disk coating, and (c) no treatment. For both the silane emulsion and silane coating 
tests, a much smoother wear scar was obtained and FTIR analysis indicated a deposit of silane was adhering to the wear scar. The ball scar from the test with no silane treatment showed a very rough surface, much more black powdery wear debris and some plastic deformation of the scar in the exit region.

Figure 6 compares the wear tracks on $440 \mathrm{C}$ stainless steel disks after very long durations of sliding under three different PFPE lubricant conditions. Shown in the figure are (a) a disk track with a silane emulsion and coating after $250 \mathrm{~km}$ of sliding, (b) a disk track with an silane coating after $237 \mathrm{~km}$ of sliding, and (c) a disk track with no silane treatment after $230 \mathrm{~km}$ of sliding. The disk track lubricated with PFPE with no treatment shows a large amount of black powdery wear debris (especially in the center of the track). The silane coated disk shows a dark material on the wear track that appears to be platelet-like. The silane emulsion shows a disk wear track that has nearly no visible deposits.

Photomicrographs of the ball wear surfaces were also taken after long durations of sliding. Figure 7 shows a low and high magnification photomicrograph of a ball wear scar after $350 \mathrm{~km}$ of sliding where the counterface was a silane coated $440 \mathrm{C}$ stainless steel disk. The ball wear scar is seen to be very smooth and the transfer is thin and "platelet-like". $\mu$ FTIR analysis of this scar showed that the transfer contained silane.

Figure 8 shows a photomicrograph of a ball wear scar after $266 \mathrm{~km}$ of sliding where no silane emulsions or coatings to the disk were employed. Dark powdery transfer is observed as well as an area where the oil is not wetting the surface. It is not certain why this phenomena occurred, but this dewetting phenomena has been observed using the PFPE lubricants on other occasions by the authors. The dewetting phenomena was not observed for any test in which silane was used as an additive or as a emulsion.

\section{Disk Surface Profilometry}

Figure 9 compares the disk wear track areas after $50 \mathrm{kc}$ of sliding for (a) PFPE oil with a silane emulsion and for a (b) PFPE oil with no treatment. The wear track area for the test with the silane emulsion has a crosssectional area of $59 \times 10^{-12} \mathrm{~m}^{2}$, while the test without the silane had a wear track with a cross-sectional area of $214 \times 10^{-12} \mathrm{~m}^{2}$.

\section{Micro-Fourier Transformation Infrared Spectroscopy}

A comparison of the $\mu$ FTIR spectrum of the PFPE film on a $440 \mathrm{C}$ disk wear track before testing (dotted line) to the $\mu$ FTIR spectrum of the PFPE fluid on a the same wear track after it had been tested for $50 \mathrm{kc}$ (solid 
line) is shown in Fig. 10. The multiple-featured C-F peak between 1100 and $1400 \mathrm{~cm}^{-1}$ and the sharp $\mathrm{CF}_{3}$ peak at $980 \mathrm{~cm}^{-1}$ (which corresponds to the $\mathrm{CF}_{3}$ rotation-vibration) are characteristic of this particular PFPE lubricant. The peak in the 3000 to $3500 \mathrm{~cm}^{-1}$ region is due to H-bonded $-\mathrm{OH}$. The broad peak at $1670 \mathrm{~cm}^{-1}$ and the small peak at $1425 \mathrm{~cm}^{-1}$, which overlaps the water vibrations, could be due to two type of structures. Liang and Roselius (18) suggested that the degradation products on the surface have a structure of perfluoroacyl fluoride bounded to the surface through a hydroxyl. Thus the peak at $1670 \mathrm{~cm}^{-1}$ could correspond to a $\mathrm{C}=\mathrm{O}$ vibration, and the $1425 \mathrm{~cm}^{-1}$ peak would then correspond to the end C-F vibration. The second possibility is the formation of a surface carboxylate, $\mathrm{COO}^{\delta}$-, formed by the reaction of a perfluoroacyl fluoride with a surface or ambient water. At the present time, there is not enough spectroscopic evidence to discern which is the correct structure. However, there is enough evidence to definitely state that the observed $\mu$ FTIR spectra corresponded to the signature of the degraded lubricant.

To ascertain if silane were transferred from the emulsion or coating to the mating surfaces, a $\mu$ FTIR spectrum of the silane coating was taken before testing and then compared to deposits on the ball wear surfaces. Figure 11 shows the $\mu$ FTIR spectrum of the silane coating applied to a $440 \mathrm{C}$ steel surface. The two sharp bands at 3367 and $3298 \mathrm{~cm}^{-1}$ are typical $\mathrm{N}-\mathrm{H}$ asymmetric and symmetric stretching vibrations which occur in $\mathrm{NH}_{2}$ groups. The band at $1600 \mathrm{~cm}-1$ is the corresponding deformation vibration. Hydrogen bonding is typical in the solid or liquid state for compounds containing $\mathrm{NH}_{2}$ groups. Thus hydrogen bonding accounts for the broad peak between 3000 and $3500 \mathrm{~cm}^{-1}$. Since this film has been baked after its application to the $440 \mathrm{C}$ surface, it is unlikely that this broad vibration would be due to H-bonding of hydroxyl groups. Other peaks present are the $\mathrm{C}$ - $\mathrm{H}$ stretching vibrations due to the $\mathrm{C}_{2} \mathrm{H}_{5}$ and the $\mathrm{C}_{3} \mathrm{H}_{6}$ groups which appear at 2840 and $2932 \mathrm{~cm}^{-1}$, respectively. The band at $1470 \mathrm{~cm}^{-1}$ is the corresponding deformation vibration. The Si-O- $\mathrm{C}_{2} \mathrm{H}_{5}$ vibrations appear at 1100 and $930 \mathrm{~cm}^{-1}$ and the $\mathrm{Si}-\mathrm{C}_{3} \mathrm{H}_{6}$ appear at $792 \mathrm{~cm}^{-1}$.

Figure 12 compares the $\mu$ FTIR spectra (in the 5000 to $1500 \mathrm{~cm}^{-1}$ wavenumber region) from spectra taken from wear scars which were slid against silane coated disks. Spectra are shown for a (a) short duration test $(50 \mathrm{kc})$ and for a (b) long duration test $(4300 \mathrm{kc})$. The spectrum for the short duration test shows the presence silane peaks (C-H and $\mathrm{N}-\mathrm{H}$ vibrations) but does not show any PFPE decomposition peaks (-OH and $\mathrm{C}=\mathrm{O}$ vibrations). The long duration spectrum shows no silane peaks but does show the presence of PFPE decomposition peaks. The -OH 
vibration ( 3500 to $3000 \mathrm{~cm}^{-1}$ ) is very shallow and is somewhat hidden in the broad peak shown on Figure 12; however, the other degradation signature peak ( $\mathrm{C}=\mathrm{O}$ vibration) is very visible on the figure at $1625 \mathrm{~cm}^{-1}$. The presence of silane peaks on the surface and the absence of decomposition peaks (after the short sliding interval) strongly infer that the silane has helped mitigate the degradation of the PFPE. The absence of silane peaks (after the long sliding duration) indicates that the silane coating eventually wears away.

All the tests using silane showed a reduction in degradation of the PFPE lubricant for the short sliding durations. However, no silane peaks could be found on the wear surfaces for the tests using the silane emulsion. It may be that the interaction of the silane in this case took place between the PFPE and the silane and that transfer of the silane to the wear surfaces was not necessary to prevent degradation.

\section{CONCLUDING REMARKS}

The purpose of this study was to determine if a silane added to a PFPE as an emulsion or applied as a coating to the counterfaces would reduce wear and/or the degradation of a PFPE lubricant. It was found that both wear and degradation were reduced. The authors believe that reduced degradation of the lubricant leads to reduced wear, although there is no experimental proof of this.

In addition, it is important to bear in mind that no attempt has been made in this study to optimize the method of applying the coatings, the thickness of the coatings, the curing of the coatings, or the amount of the silane in the emulsion. Thus, it may be possible to obtain even better results once an optimization study is done. It also should be noted that the silane emulsions and coatings are not necessarily the same. The emulsions were not heat treated while the coatings were heat treated at $200^{\circ} \mathrm{C}$ for 30 minutes. Heat treating of the silane may have changed its structure.

Also one must be aware that accelerated test data such as wear rates, friction coefficients, etc. do not necessarily directly correlate to results achieved in an actual bearing. A very small improvement in an accelerated test data may lead to a very large improvement in a bearing or there may be very little improvement. A test using bearings must be made to ascertain the real improvement. Screening tests, such as pin-on-disk tests, are done to show potential of various concepts for use in a bearing. 


\section{SUMMARY OF RESULTS}

Pin-on-disk tribology testing coupled with surface profilometry, optical microscopy and $\mu$ FTIR studies on a PFPE liquid lubricant with and without silane additives and/or emulsions indicate that:

(1) Silane coatings and/or emulsions used in conjunction with PFPE oils eliminated PFPE degradation products which were found on ball wear surfaces on tests with the untreated oil, giving strong evidence that the silane can mitigate the degradation of this particular PFPE oil.

(2) Accompanying the reduced degradation of the PFPE oil was reduced wear of $440 \mathrm{C}$ balls and disks when compared to similar tests on an untreated PFPE oil.

(2) Equal improvements in decreased wear rates were obtained for disk coatings and oil emulsions; although no attempt was made to optimize either application method.

(3) Optical and $\mu$ FTIR microscopy observations indicated that the silane disk coatings could form thin layerlike transfer films on ball wear surfaces.

(5) Friction coefficients obtained from PFPE oil tests using silane emulsions or silane coatings were the same as those obtained from tests using the untreated PFPE oil. 


\section{REFERENCES}

1. Gumprecht, W.H., "PR-143-A New Class of High Temperature Fluids," ASLE Trans, 9, pp.24-30 (1966).

2. Sianesi, D., Chim. Ind. (Milan), 50, p.206 (1968).

3. Holland, L., Laurenson, L., and Baker, P.N., Vacuum, 22, p.315 (1972).

4. Luches, A., and Provenzano, I., J. Phys. D: Appl. Phys., 10, p.339 (1977).

5. Sianesi, D., Zamboni, V., Fontanelli, R, and Binaghi, M., "Perfluoropolyethers: Their Physical Properties and Behaviour at High and Low Temperatures," Wear, 18, p.85-100 (1971).

6. Sharma, S.K., Gschwender, L.J., and Snyder, C.E., Jr., "Development of a Soluble Lubricity Additive for Perfluoropolyalkylether Fluids," Journal of Synthetic Lubrication, 7, 1, pp.15-23 (1990).

7. Gschwender, L.J., Snyder, C.E. Jr., and Fultz, G.W., "Soluble Additives for Perfluoropolyalkylether Liquid Lubricants," Lub. Eng., 49, 9, pp.702-708 (1993).

8. Carré, D.J., and Markowitz, J.A., "The Reaction of PFPE Oil with FeF3, AlF3, and AlCl3 at Elevated Temperatures," ASLE Trans., 28, 1, pp.40-46 (1985).

9. Zehe, M.J., and Faut, O.D., "Acidic Attack of PFPE Lubricant Molecules by Metal Oxide Surfaces," NASA TM-101962 (1993).

10. Kasai, P.H., Tang, W.T., and Wheeler, P.O., "Degradation of PFPE's Catalyzed by Aluminum Oxide," Applied Surface Science, 51, pp.201-211 (1991).

11. Basu, P., Ballinger, T.H., and Yates, J.T. Jr., " Fluoroalkyl Ether Chemistry on Alumina: A transmission IR Study of the Adsorption and Thermal Decomposition of (CF2H)2O on Al2O3," Langmuir, 5, 2, pp.502-510 (1989).

12. Ng, L.M., Lyth, E., Zeller, M.V., and Boyd, D.L., "Surface Chemistry of Perfluoro Ethers: An Infrared Study of the Thermal Decomposition of (C2F5)2O on Al203," Langmuir, pp.127-135 (1995).

13. Morales, W., "Perfluoropolyalkylether Decomposition on Catalytic Aluminas," NASA TM 106547 (1994).

14. Fusaro, Robert, L., "How to Evaluate Solid-Lubricant Films Using a Pin-on-Disk Tribometer," Lubr. Eng., 43, 5, pp.330-338 (1987).

15. Hollis, Peter, "Surface Infrared Spectroscopy," Vacuum, 45, pp.705-714 (1994). 
16. Porter, M.D., "IR External Reflection Spectroscopy: A Probe for Chemically Modified Surfaces," Analytical Chem., 60, pp. 1143A-1155A (1988).

17. Reffner, J.A., "Infrared Microanalysis of Contaminants at Grazing Incidence," Applied Spectroscopy in Material Science, 1437, pp.89-94 (1991).

18. Liang. J., and Roselius, M., "FTIR Study of Perfluoroacyl Fluoride Chemisorption onto Alumina," J. of Fluorine Chemistry, 67, pp.113-117 (1994).

TABLE 1 . - PROPERTIES OF PFPE AND SILANE LIQUIDS.

\begin{tabular}{|l|l|c|}
\hline PROPERTY & \multicolumn{1}{|c|}{ PFPE } & ORGANOSILANE \\
\hline Average Molecular Weight & 11,000 & 221.37 \\
\hline Density (g/cm3) & $1.92\left(20^{\circ} \mathrm{C}\right)$ & $0.941\left(20^{\circ} \mathrm{C}\right)$ \\
\hline Refractive Index & $<1.3\left(20^{\circ} \mathrm{C}\right)$ & $1.421\left(20^{\circ} \mathrm{C}\right)$ \\
\hline Viscosity (cST) & $2717\left(20^{\circ} \mathrm{C}\right)$ & $-\cdots$ \\
& $63\left(100^{\circ} \mathrm{C}\right)$ & \\
\hline Vapor Pressure (Torr) & $3310^{-14}\left(20^{\circ} \mathrm{C}\right)$ & \\
& $13^{-9}\left(100^{\circ} \mathrm{C}\right)$ & \\
\hline Pour Point $\left({ }^{\circ} \mathrm{C}\right)$ & -15 & $-\cdot-$ \\
\hline Boiling Point $\left({ }^{\circ} \mathrm{C}\right)$ & None & 217 \\
\hline Flash Point $\left({ }^{\circ} \mathrm{C}\right)$ & None & 104 \\
\hline
\end{tabular}


TABLE 2 - COMPARISON OF BALL WEAR RATES FOR SHORT AND LONG DURATION TESTS

[Experimental conditions: Temperature, $25^{\circ} \mathrm{C}$; dry air Atmosphere (100 ppm Moisture C ontent; Load, 2 kg; Speed, 200 rpm; $440 \mathrm{C}$ Stainless Steel Specimens.]

\begin{tabular}{|c|c|c|c|c|c|c|c|c|c|c|}
\hline \multirow{3}{*}{$\begin{array}{l}\text { OIL, DISK OR BALL } \\
\text { TREATMENT }\end{array}$} & \multicolumn{5}{|c|}{ SHORT TERM TESTS $(0$ to $30 \mathrm{kc})$} & \multicolumn{5}{|c|}{ LONG TERM TESTS $(50$ to $4500 \mathrm{kc})$} \\
\hline & \multirow[t]{2}{*}{$\begin{array}{l}\text { NUMBER } \\
\text { OF TESTS } \\
\end{array}$} & \multicolumn{4}{|c|}{$\begin{array}{c}\text { PIN WEAR RATE } \\
(\mathrm{m} 3 / \mathrm{m})\end{array}$} & \multirow[t]{2}{*}{$\begin{array}{l}\text { NUMBER } \\
\text { OF TESTS }\end{array}$} & \multicolumn{4}{|c|}{$\begin{array}{c}\text { PIN WEAR RATE } \\
\left(\mathrm{m}^{3 / \mathrm{m}}\right)\end{array}$} \\
\hline & & MAXIMUM & MINIMUM & MEDIAN & $\begin{array}{l}\text { STANDARD } \\
\text { DEVIATION } \\
\end{array}$ & & $\begin{array}{c}\text { MAXIMU } \\
\mathrm{M} \\
\end{array}$ & MINIMUM & MEDIAN & $\begin{array}{l}\text { STANDARD } \\
\text { DEVIATION }\end{array}$ \\
\hline NONE & 6 & $455 \times 10^{-18}$ & $131 \times 10^{-18}$ & $240 \times 10^{-18}$ & $120 \times 10^{-18}$ & 7 & $40 \times 10^{-18}$ & $23 \times 10^{-18}$ & $48 \times 10^{-18}$ & $31 \times 10^{-18}$ \\
\hline OIL EMULSION & 6 & 129 & 21 & 81 & 36 & 4 & 45 & 21 & 31 & 13 \\
\hline COATING (DISK) & 8 & 139 & 34 & 84 & 34 & 6 & 49 & 15 & 27 & 12 \\
\hline $\begin{array}{l}\text { COATING (DISK \& } \\
\text { BALL) }\end{array}$ & 3 & 134 & 62 & 91 & 38 & 2 & 18 & 9 & 14 & 6 \\
\hline $\begin{array}{l}\text { OIL EMULSION/ } \\
\text { COATING (DISK) }\end{array}$ & 4 & 79 & 51 & 65 & 12 & 4 & 29 & 10 & 21 & 8 \\
\hline $\begin{array}{l}\text { OIL EMULSION/I } \\
\text { COATING ( DISK \& } \\
\text { BALL) }\end{array}$ & 2 & 120 & 93 & 107 & 19 & 2 & 16 & 9 & 12 & 5 \\
\hline
\end{tabular}

TABLE 3 -COMPARISON OF FRICTION COEFFICIENTS FOR SHORT AND LONG DURATION TESTS

[Experimental Conditions: Temperature, $25^{\circ} \mathrm{C}$; Dry Air Atmosphere (100 ppm Moisture Content); Load, $2 \mathrm{~kg}$; Speed, 200 rpm; $440 \mathrm{C}$ Stainless Steel Specimens.]

\begin{tabular}{|c|c|c|c|c|c|c|c|c|}
\hline \multirow{3}{*}{$\begin{array}{l}\text { OIL, DISK OR BALL } \\
\text { TREATMENT }\end{array}$} & \multicolumn{4}{|c|}{ SHORT TERM TESTS $(0$ to $30 \mathrm{kc})$} & \multicolumn{4}{|c|}{ LONG TERM TESTS ( 50 TO $4500 \mathrm{kc}$ ) } \\
\hline & \multirow{2}{*}{$\begin{array}{l}\text { NUMBER } \\
\text { OF TESTS }\end{array}$} & \multicolumn{3}{|c|}{ FRICTION COEFFICIENT } & \multirow{2}{*}{$\begin{array}{l}\text { NUMBER } \\
\text { OF TESTS }\end{array}$} & \multicolumn{3}{|c|}{ FRICTION COEFFICIENT } \\
\hline & & MAXIMUM & MINIMUM & MEDIAN & & MAXIMUM & MINIMUM & MEDIAN \\
\hline NONE & 6 & 0.16 & 0.09 & $0.13 \pm .02$ & 3 & 0.17 & 0.10 & $0.14 \pm .02$ \\
\hline OIL EMULSION & 6 & 0.16 & 0.09 & $0.13 \pm .02$ & 2 & 0.17 & 0.11 & $0.14 \pm .01$ \\
\hline COATING (DISK) & 8 & 0.16 & 0.09 & $0.14 \pm .02$ & 5 & 0.16 & 0.10 & $0.13 \pm .02$ \\
\hline COATING (DISK \& BALL) & 3 & 0.17 & 0.11 & $0.14 \pm .01$ & 2 & 0.16 & 0.12 & $0.14 \pm .01$ \\
\hline $\begin{array}{l}\text { OIL EMULSION/ } \\
\text { COATING (DISK) }\end{array}$ & 4 & 0.16 & 0.10 & $0.13 \pm .02$ & 4 & 0.16 & 0.11 & $0.14 \pm .01$ \\
\hline $\begin{array}{l}\text { OIL EMULSION/ } \\
\text { COATING (DISK \& BALL) }\end{array}$ & 2 & 0.17 & 0.11 & $0.14 \pm .01$ & 2 & 0.16 & 0.13 & $0.14 \pm .01$ \\
\hline $\begin{array}{l}\text { DRY SILANE COATING (NO } \\
\text { OIL) }\end{array}$ & 2 & 0.35 & 0.18 & $0.25 \pm .05$ & $\ldots$ & $\cdots$ & $\cdots$ & $\cdots$ \\
\hline
\end{tabular}




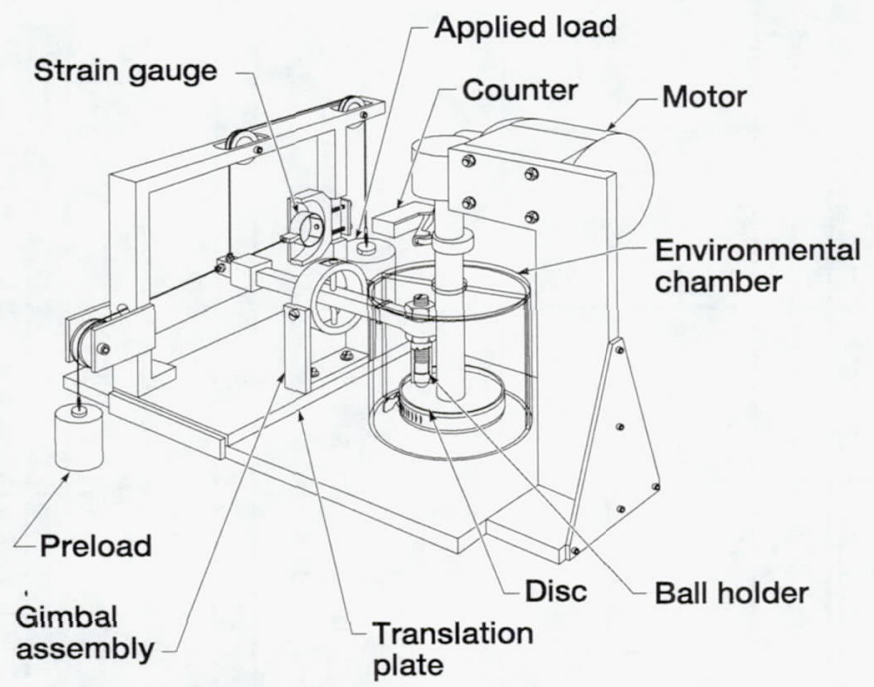

Figure 1.-Pin on disk tester.
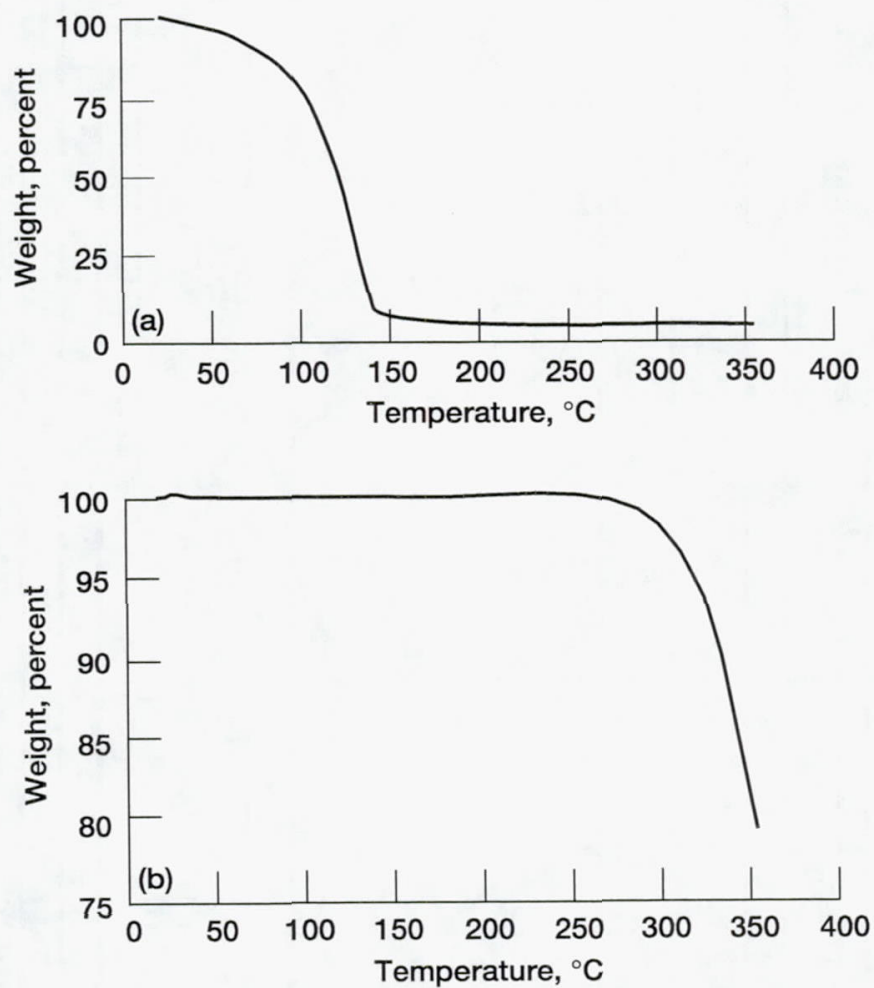

Figure 2.-Thermogravometric thermograms of the (a) Liquid silane and (b) PFPE. 


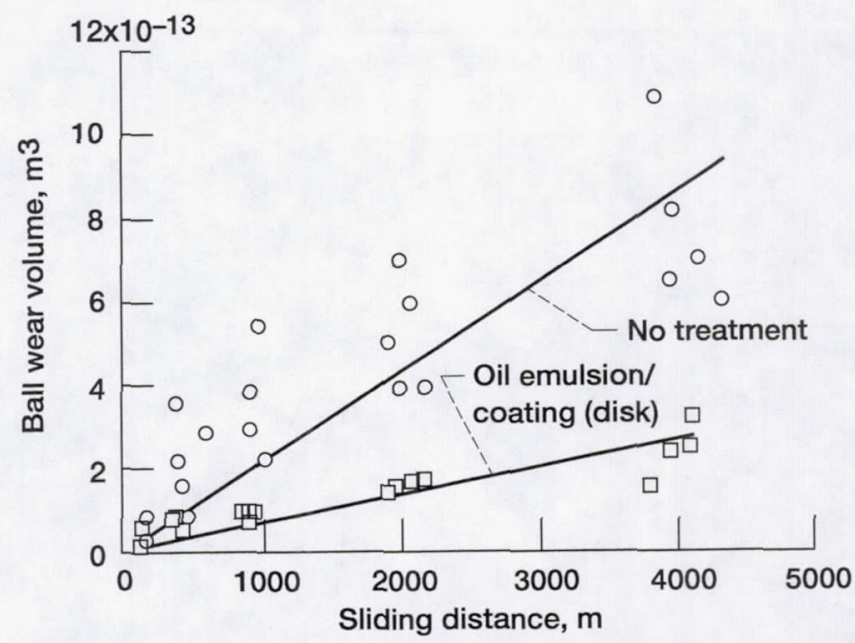

Figure 3.-Ball wear volume as a function of sliding distance for all the tests conducted on a PFPE oil with no silane treatment and for all tests conducted on the same PFPE oil treated with a silane emulsion and a disk coating. The lines shown represent least squares regression fits of the data which was forced to intersect the origin.
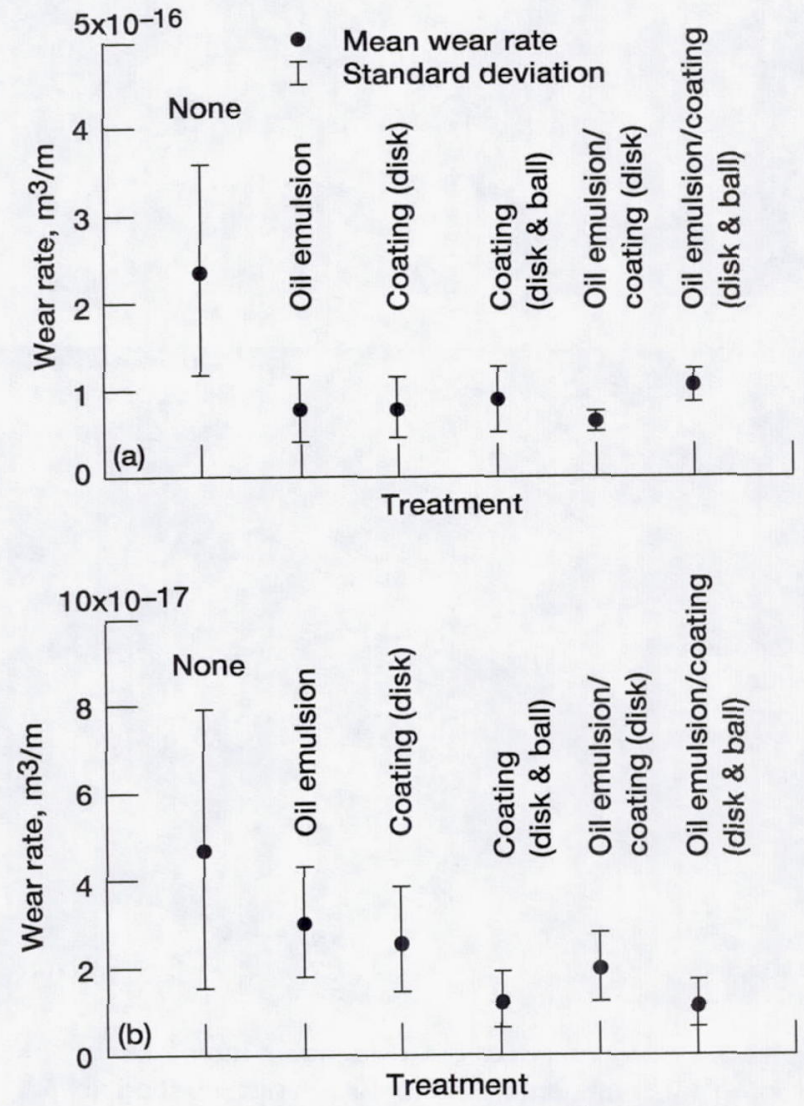

Figure 4.-Comparison of mean ball wear rates and standard deviations for the (a) short term and (b) long term test intervals. 

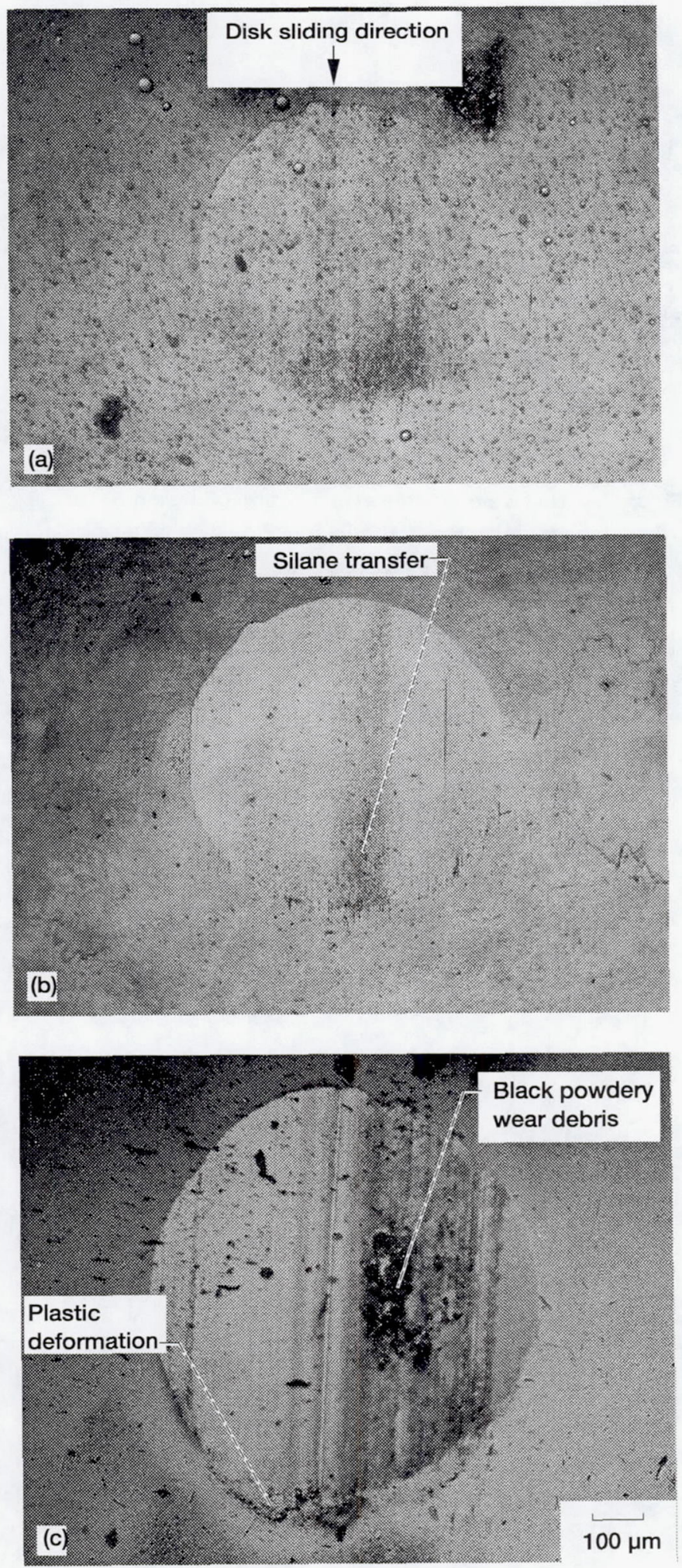

Figure 5.-Comparison of ball wear scars after $2 \mathrm{~km}$ of sliding. (a) Silane emulsion. (b) Silane disk coating. (c) No silane treatment. 
Pin sliding

direction

$\downarrow$
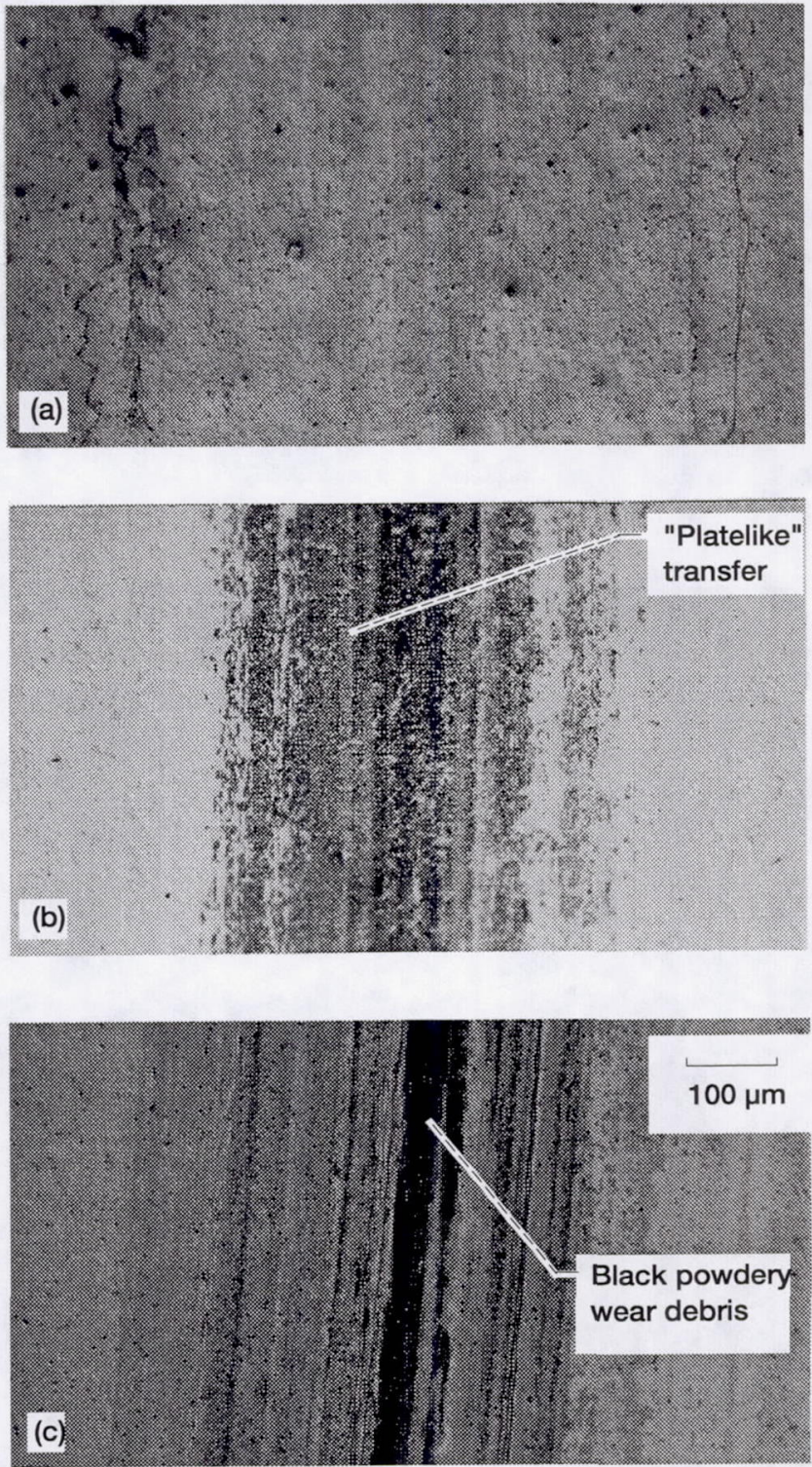

Figure 6.-Comparison of wear tracks on $440 \mathrm{C}$ stainless steel disks after very long durations of sliding. (a) Silane emulsion and coating $(250 \mathrm{~km})$. (b) Silane disk coating $(237 \mathrm{~km})$. (c) No silane treatment $(230 \mathrm{~km})$. 

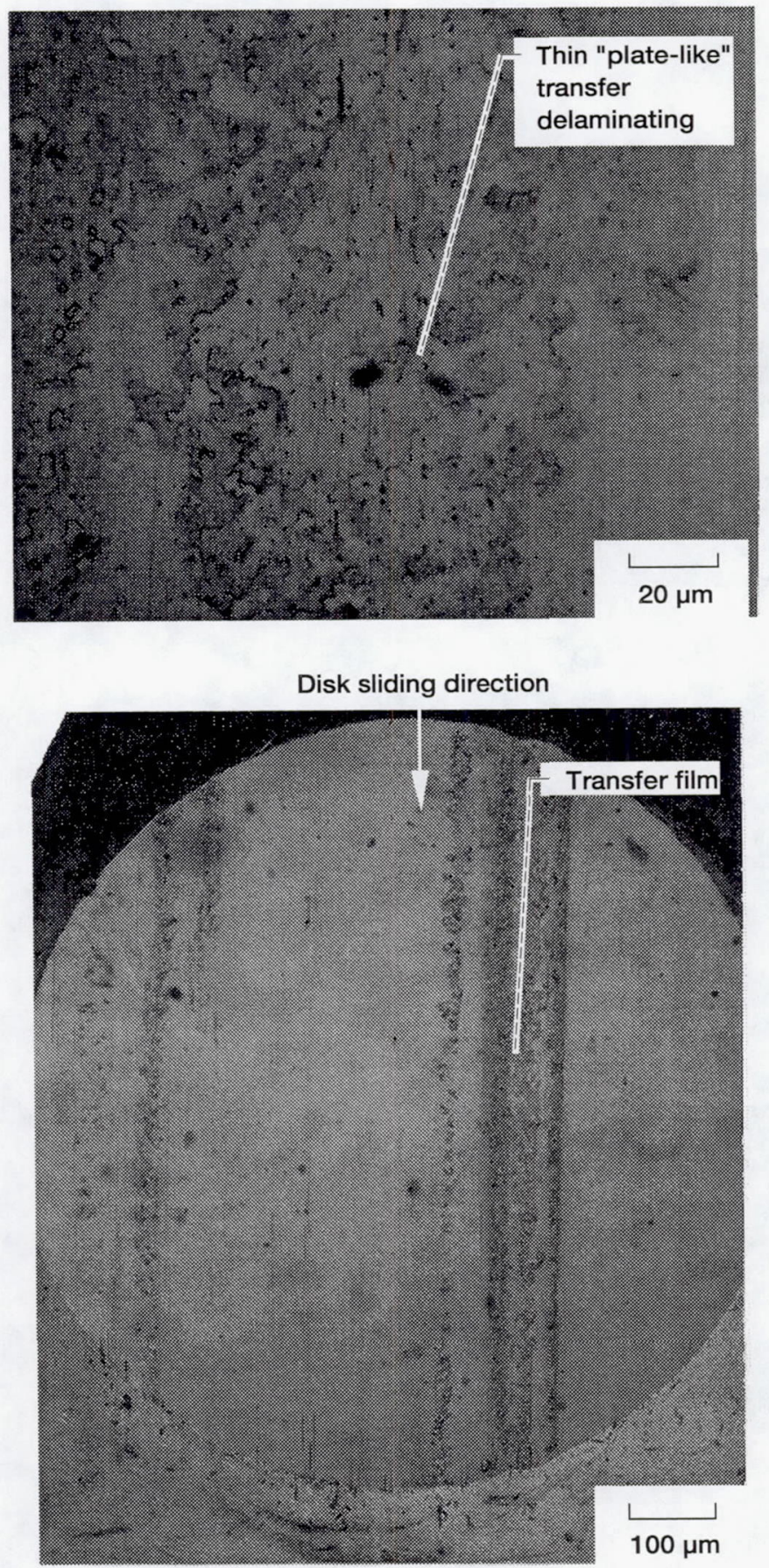

Figure 7.-Low and high magnification photomicrogrphs of ball wear scar areas after $350 \mathrm{~km}$ of sliding from a test where the counterface was a silane coated $440 \mathrm{C}$ stainless steel disk. 


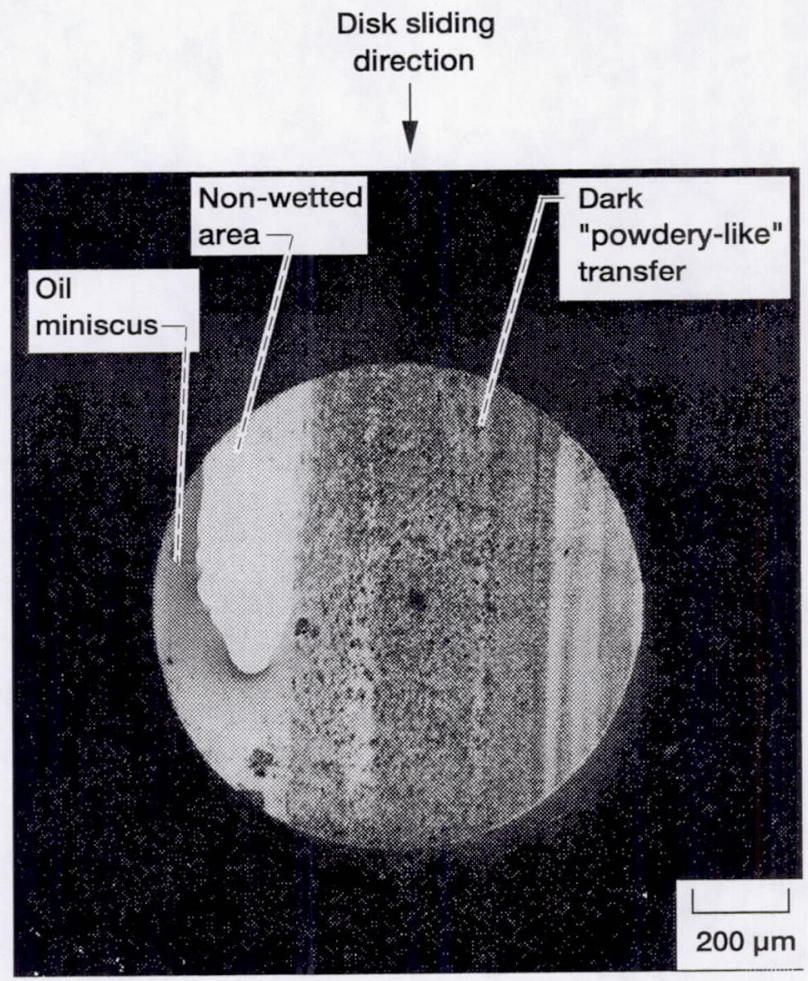

Figure 8.-Photomicrograph of a ball wear scar after $266 \mathrm{~km}$ of sliding from a test where no silane emulsions or coatings to the disk were employed. Dewetting of the oil from the surface can be observed.
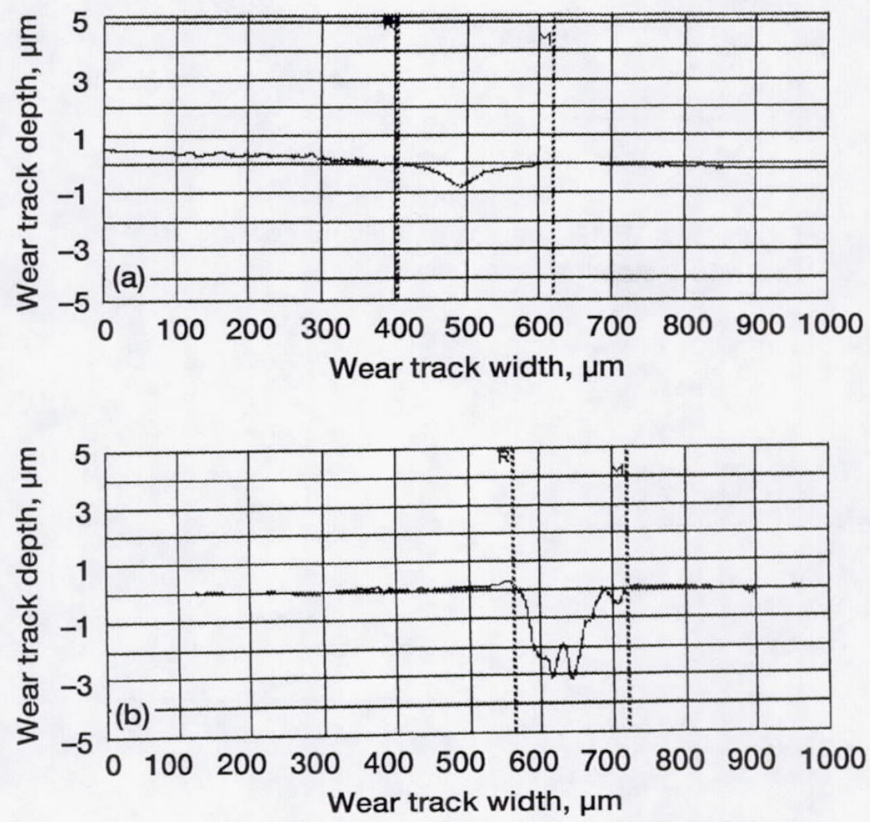

Figure 9.-Comparison of disk wear track cross-sectional areas after $50 \mathrm{kc}$ of sliding for tests conducted in (a) a PFPE oil with a silane dispersion and (b) a PFPE oil with no silane dispersions or coatings. 


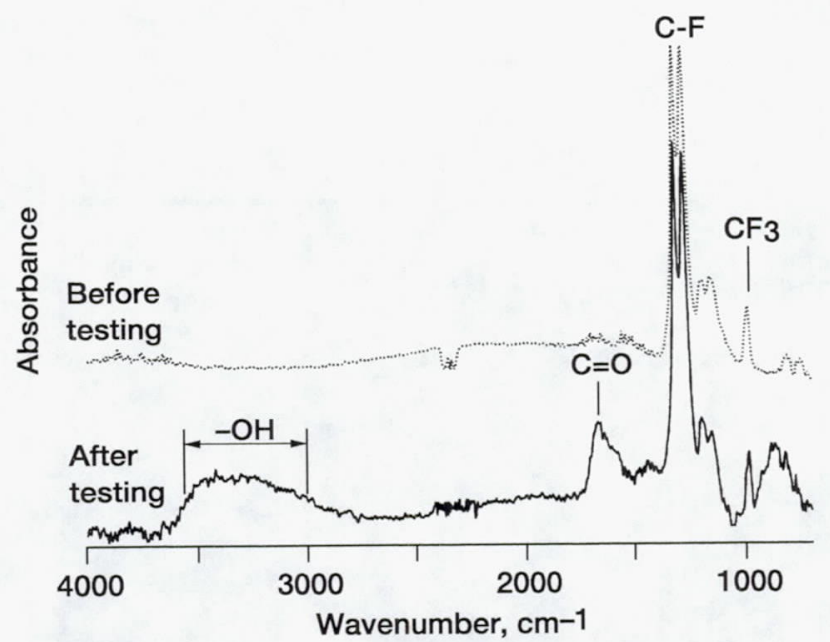

Figure 10.-Comparison of FTIR spectra of PFPE oil on a $440 \mathrm{C}$ stainless steel ball before testing to that obtained on the $440 \mathrm{C}$ steel ball wear scar after 50 kilocycles of sliding (no treatment of the oil).

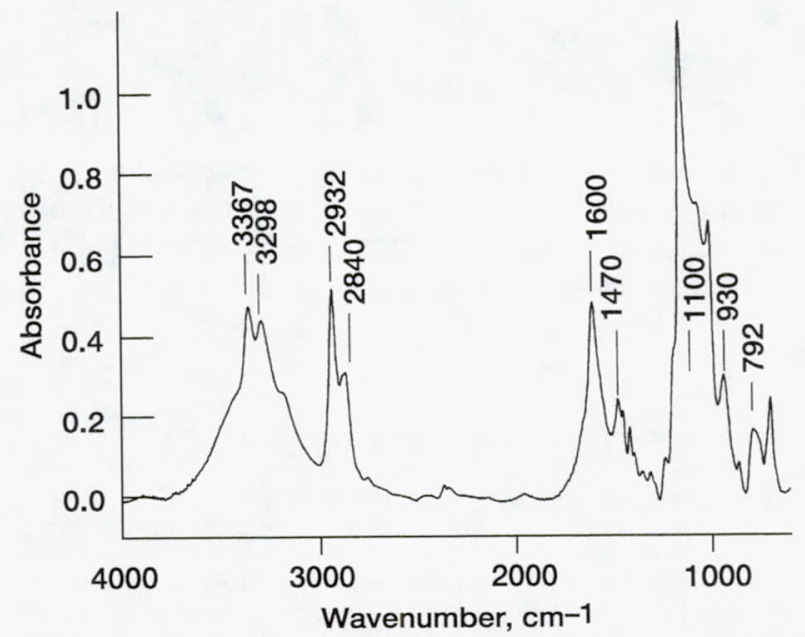

Figure 11.-FTIR spectra of a silane coating applied to a $440 \mathrm{C}$ stainless steel disk.

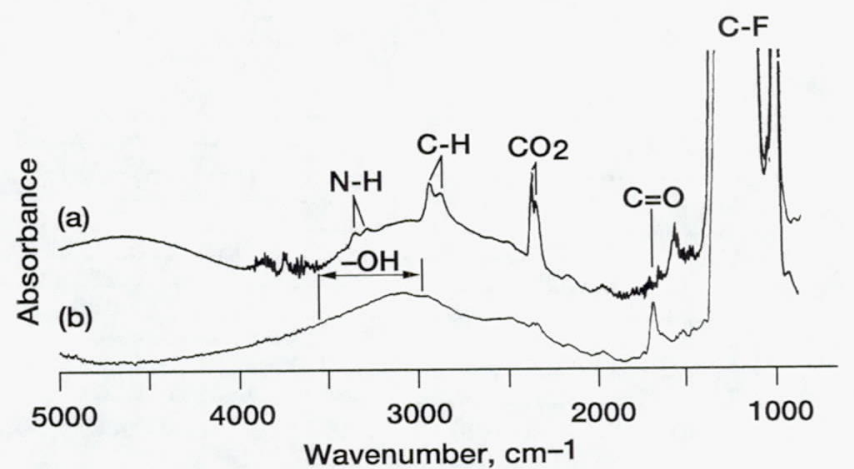

Figure 12.-Comparison of FTIR spectra obtained from ball deposits on the wear scar after (a) 50 kilocycles and after (b) 4300 kilocycles of sliding on a silane coated disk. $(-\mathrm{OH}$ and $\mathrm{C}=\mathrm{O}$ are PFPE decomposition peaks, $\mathrm{N}-\mathrm{H}$ and $\mathrm{C}-\mathrm{H}$ are silane peaks.) 


\section{REPORT DOCUMENTATION PAGE}

Public reporting burden for this collection of information is estimated to average 1 hour per response, including the time for reviewing instructions, searching existing data sources,

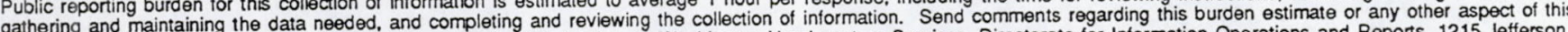
gathering and maintaining the data needed, and completing and reviewing Washington Headquarters Services, Directorate for Information Operations and Reports, 1215 Jefferson Davis Highway, Suite 1204, Arlington, VA 22202-4302, and to the Office of Management and Budget, Paperwork Reduction Project (0704-0188), Washington, DC 20503.

\begin{tabular}{|l|c|c|}
\hline 1. AGENCY USE ONLY (Leave blank) & $\begin{array}{c}\text { 2. REPORT DATE } \\
\text { December 1995 }\end{array}$ & $\begin{array}{r}\text { 3. REPORT TYPE AND DATES COVERED } \\
\text { Technical Memorandum }\end{array}$
\end{tabular}

4. TITLE AND SUBTITLE

5. FUNDING NUMBERS

A New Antiwear Additive/Surface Pretreatment for PFPE Liquid Lubricants

Wilfredo Morales, Robert L. Fusaro, Mark Siebert, Theo Keith,

Ralph Jansen, and Pilar Herrera-Fierro

7. PERFORMING ORGANIZATION NAME(S) AND ADDRESS(ES)

PERFORMING ORGANIZATION REPORT NUMBER

National Aeronautics and Space Administration

Lewis Research Center

E-9859

Cleveland, Ohio 44135-3191

WU-322-16-04

9. SPONSORING/MONITORING AGENCY NAME(S) AND ADDRESS(ES)

10. SPONSORING/MONITORING AGENCY REPORT NUMBER

National Aeronautics and Space Administration

Washington, D.C. 20546-0001

NASA TM-107038

11. SUPPLEMENTARY NOTES

Wilfredo Morales and Robert L. Fusaro, NASA Lewis Research Center; Mark Siebert and Theo Keith, University of Toledo, Toledo, Ohio 43606; Ralph Jansen and Pilar Herrera-Fierro, Ohio Aerospace Institute, 22800 Cedar Point Road, Brook Park, Ohio 44142. Responsible person, Robert L. Fusaro, organization code 5230, (2160 433-6080).

12a. DISTRIBUTION/AVAILABILITY STATEMENT

12b. DISTRIBUTION CODE

Unclassified -Unlimited

Subject Category 27

This publication is available from the NASA Center for Aerospace Information, (301) 621-0390.

13. ABSTRACT (Maximum 200 words)

Pin-on-Disk tribology experiments were conducted on a perfluoroalkylether (PFPE) liquid lubricant with and without a new PFPE lubricant antiwear additive material, a silane. It was found that the silane provided moderate improvement in the antiwear performance of the PFPE lubricant when applied to the metallic surface as a surface coating or when added to the PFPE as a dispersion (emulsion). Slightly better results were obtained by using the combination of a surface coating and an emulsion of the silane. The silane emulsions or coatings did not affect the friction properties of the lubricant. Micro-Fourier Transformation Infrared ( $\mu$ FTIR) spectroscopy analysis was performed to study silane transfer films and the degradation of the PFPE. The silane was found to mitigate degradation of the PFPE which may have been the major reason for the improved antiwear performance observed.

\begin{tabular}{|c|c|c|}
\hline \multicolumn{3}{|l|}{ 14. SUBJECT TERMS } \\
\hline \multicolumn{3}{|c|}{ Tribology; Lubricant; PFPE; Additives; Wear; Decomposition; Space systems; Aircraft } \\
\hline $\begin{array}{l}\text { 17. SECURTYY CLASSIFICATION } \\
\text { OF REPORT }\end{array}$ & $\begin{array}{l}\text { 18. SECURITY CLASSIFICATION } \\
\text { OF THIS PAGE } \\
\text { Unclassified }\end{array}$ & $\begin{array}{l}\text { 19. SECURITY CLASSIFICATION } \\
\text { OF ABSTRACT } \\
\text { Unclassified }\end{array}$ \\
\hline & & \\
\hline
\end{tabular}

